\title{
Direct Polyesterification of Pyridine-2,6-Dicarboxylic Acid and Poly(ethylene glycol) using Picryl Chloride as Condensing Agent
}

\author{
Nhung T.H. Doan, Véronique Montembault and Jean-Claude Soutif*
}

UCO2M, LCOM-Chimie des Polymères, UMR 6011 CNRS-Université du Maine, Avenue O. Messiaen - 72085 Le Mans Cedex 9 - France; Fax 0033243833754; jean-claude.soutif@univ-lemans.fr

(Received: 19 May, 2006 ; published : 18 August, 2006)

\begin{abstract}
High molecular weight polyesters derived from pyridine-2,6-dicarboxylic acid and poly(ethylene glycol) have been synthesized under mild conditions (room temperature, atmospheric pressure) in the presence of picryl chloride and pyridine. Reaction conditions including solvent, trap agent, reaction time and amount of reagents were investigated using poly(ethylene glycol) 400 as dialcohol comonomer. Detailed analysis of the MALDI-TOF mass spectra of the obtained polyesters has revealed a predominant fraction of macrocycles for a picryl chloride/acid functions molar ratio lower than 1.5. The reaction yielded the most favourable results using 1.5 equivalents of picryl chloride with respect to the acid functions and 4-( $N, N$-dimethylamino)pyridine as $\mathrm{HCl}$ scavenger. The molecular weights of the polyesters at the peak maximum of the SEC trace are in the range of 4 800-80 000 depending on the nature of the comonomer poly(ethylene glycol). Syntheses of an aliphatic and aromatic polyester were also examined.
\end{abstract}

\section{Introduction}

Polyesters are generally prepared by transesterification between diesters and dialcohols in the melt at temperature above $200^{\circ} \mathrm{C}$ under vacuum $[1,2]$. Several works have been developed for the synthesis of polyesters under mild conditions. Methods using prior activation of the diacid monomer into diacid dichloride [1] or diester [4-6] can be useful but are limited by the low nucleophilicity of the hydroxyl groups [7]. Direct polyesterification of dicarboxylic acid and diol using a condensing agent under mild conditions has also been reported. Poly(ether-ester)s of pyridine2,6-dicarboxylic acid and poly(ethylene glycol)s were prepared by direct polycondensation using dicyclohexylcarbodiimide at room temperature [3], but only low molecular weight polycondensates were obtained. A high number-average molecular weight $\left(\bar{M}_{n}>100000\right)$ polyester was obtained from polyesterification of bisphenol and a mixture of isophthalic and terephthalic acid at $80^{\circ} \mathrm{C}$ in presence of thionyl chloride [8, 9]. Tosyl chloride [10], arylsulfonyl chlorides [11] and triphenylphosphine [7] have also proved their efficiency as condensing agents for the polyesterification of aromatic comonomers.

Takimoto et al. [12] have also reported the direct condensation of an acid and an alcohol using picryl chloride as condensing agent in organic solvents in the presence of a base. Tanaka et al. [13-14] have afterwards applied this method to 
polycondensation. The obtained polyesters from the aromatic comonomers bisphenol A and pyridine-2,5-dicarboxylic acid show good results in terms of both polymer yield and solution viscosity.

In this paper, we describe the detailed results of the direct polycondensation of pyridine-2,6-dicarboxylic acid and various poly(ethylene glycol)s using picryl chloride as a condensing agent. Reaction conditions have been investigated in order to obtain polycondensates with high molecular weight to allow study of their complexing properties. Afterwards, this reaction has been successfully applied to the preparation of aliphatic and of aromatic polyesters.

\section{Results and discussion}

Direct polycondensation from pyridine-2,6-dicarboxylic acid and PEG 1000 was first performed in the same reaction conditions as described in the literature [13], i.e., by using equimolar ratio between the diacid and the diol in pyridine as solvent and as base. The picryl chloride $(\mathrm{PCl})$ condensing agent is used in a molar ratio of 1.25 with regard to acid functions (Scheme 1 ).

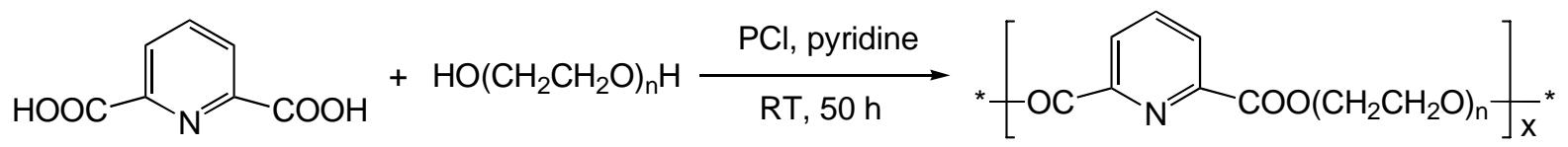

Scheme 1. Polycondensation of pyridine-2,6-dicarboxylic acid and PEG.

The obtained results compiled in Tab. 1 show an increase of both conversion and number-average molecular weight $\left(\overline{\mathrm{M}_{n}}\right)$ with reaction time up to $12 \mathrm{~h}$.

Tab. 1. Number-average molecular weight $\left(\overline{M_{n}}\right)$, polydispersity index (PDI) and conversion versus time of the polycondensation between pyridine-2,6-dicarboxylic acid and PEG 1000 in the presence of PCl in pyridine at room temperature.

\begin{tabular}{ccccc}
\hline Time $(\mathrm{h})$ & $\overline{\mathrm{M}}_{\mathrm{n}}{ }^{\mathrm{a}}$ & $\mathrm{M}_{\mathrm{p}}^{\mathrm{a}, \mathrm{b})}$ & PDI & Conversion $^{\mathrm{c})}(\%)$ \\
\hline 2 & 10400 & 7700 & 2.4 & 72 \\
6 & 11300 & 7800 & 2.4 & 76 \\
12 & 11800 & 20000 & 2.5 & 88 \\
17 & 17900 & 25000 & 2.2 & 91 \\
20 & 18500 & 13500 & 2.1 & 91 \\
35 & 21000 & 28500 & 2.1 & 91 \\
50 & 19600 & 40000 & 1.7 & 91
\end{tabular}

a) Obtained by SEC calibrated with polystyrene standards. b) Mp: molecular weight at the peak maximum of the SEC trace. c) Obtained from the PEG concentration determined by SEC according a procedure already reported [6]. 
The final polyester is obtained in a good yield $(90 \%)$ and reaches a $\overline{M_{n}}$ of 19600 after a reaction time of $50 \mathrm{~h}$. These results are higher than those observed from direct polycondensation activated by dicyclohexylcarbodiimide $\left(\overline{\mathrm{M}_{n}}=5500\right.$, conversion $=67 \%, \mathrm{t}=96 \mathrm{~h}$ ). This "in situ" activation of acid functions into acid chloride functions is also more efficient than the previous activation of the diacid monomer into diester [6] $\left(\overline{\mathrm{M}}_{\mathrm{n}}=9200 \mathrm{~g} \cdot \mathrm{mol}^{-1}, \mathrm{t}=120 \mathrm{~h}\right)$ or diacid dichloride [3] $\left(\overline{\mathrm{M}_{\mathrm{n}}}=\right.$ $7030, \mathrm{t}=20 \mathrm{~h}$ ).

In order to study the optimum condition for the polyester synthesis, we have investigated the influence of the amount of picryl chloride $(\mathrm{PCl})$ relative to the diacid. For this purpose, polycondensation between pyridine-2,6-dicarboxylic acid and PEG 400 was conducted in the presence of various molar ratios of $\mathrm{PCl}$, whereas all other parameters were kept constant. PEG 400 has been chosen because it allows following of the polycondensation by MALDI-TOF MS easily up to a molecular weight of 5000 corresponding to a number of repeating units around 10.

The results summarized in Tab. 2 show that the molecular weight passes through a maximum around a $[\mathrm{PCl}] /[\mathrm{COOH}]$ molar ratio of $1.5\left(\mathrm{n}^{\circ} 7\right.$, Table 2$)$.

Tab. 2. Effect of $[\mathrm{PCl}] /[\mathrm{COOH}]$ molar ratio on the molecular weights of the polyesters obtained from pyridine-2,6-dicarboxylic acid and PEG 400 after a reaction time of $50 \mathrm{~h}$ at room temperature.

\begin{tabular}{ccccc}
\hline Exp. No. & {$[\mathrm{PCl}] /[\mathrm{COOH}]$} & $\left.\overline{\mathrm{M}}_{\mathrm{n}}{ }^{\mathrm{a}}\right)$ & $\mathrm{M}_{\mathrm{p}}^{\mathrm{a}, \mathrm{b})}$ & $\mathrm{PDI}$ \\
\hline 1 & 0.5 & 1600 & 1400 & 1.1 \\
2 & 0.75 & 2000 & 1400 & 1.4 \\
3 & 1.0 & 2100 & 2300 & 1.4 \\
4 & 1.125 & 2500 & 2900 & 1.3 \\
5 & 1.25 & 2600 & 4000 & 2.4 \\
6 & 1.375 & 13200 & 12700 & 1.3 \\
7 & 1.5 & 33100 & 39400 & 3.2 \\
8 & 1.625 & 20400 & 15100 & 2.3 \\
9 & 2.0 & 2800 & 3100 & 1.4
\end{tabular}

a) obtained by SEC calibrated with polystyrene standards. b) Mp: molecular weight at the peak maximum of the SEC trace.

A molar ratio lower than 1.5 doesn't allow to activate completely the two acid functions as shown by the ${ }^{13} \mathrm{C}$ NMR spectra with $[\mathrm{PCl}] /[\mathrm{COOH}]$ molar ratios varying from 0.5 to 1.5 (Fig. 1).

For $[\mathrm{PCl}] /[\mathrm{COOH}]$ molar ratios from 0.5 to 1 , the peak of the acid functions was easily detected at $168.5 \mathrm{ppm}$. On the contrary, for a $[\mathrm{PCl}] /[\mathrm{COOH}]$ molar ratio $=1.5$, this peak has disappeared and the peak of the acid chloride functions was detected at $162.9 \mathrm{ppm}$. This activation results from an equilibrium since identical ${ }^{13} \mathrm{C}$ NMR spectra are obtained after $72 \mathrm{~h}$.

In Fig. 2 a typical MALDI-TOF mass spectrum of the polyester obtained from pyridine-2,6-dicarboxylic acid and PEG 400 in pyridine with a $[\mathrm{PCl}] /[\mathrm{COOH}]$ molar ratio of 1.25 is presented. 


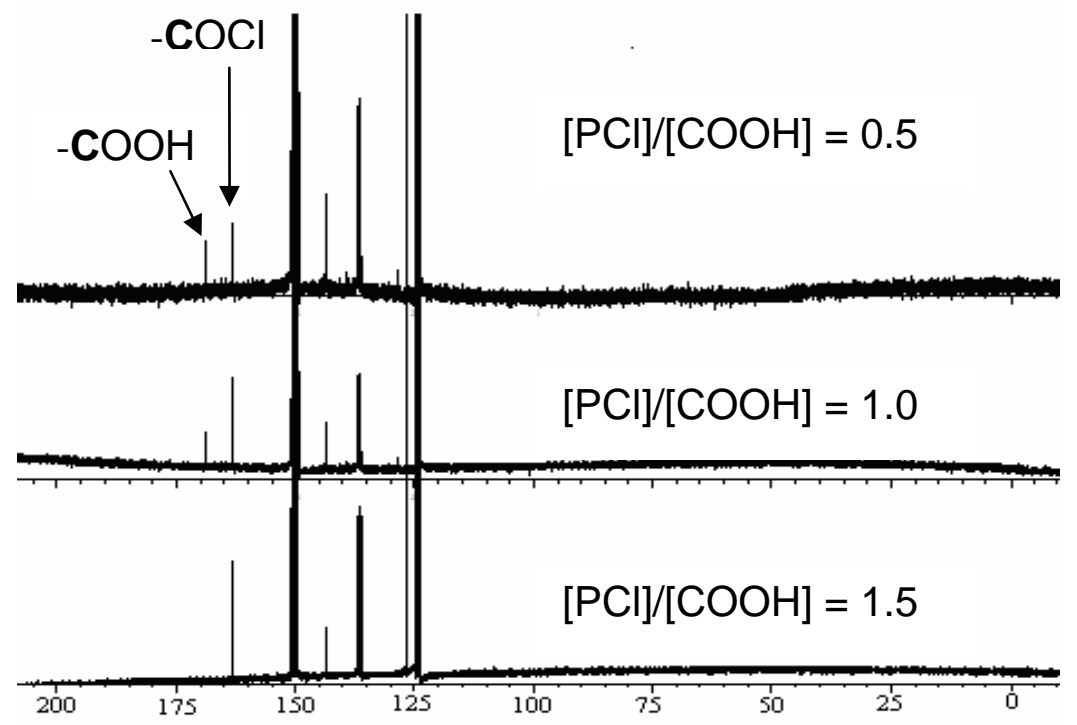

Fig. $1 .{ }^{13} \mathrm{C}$ NMR spectra of mixtures of pyridine-2,6-dicarboxylic acid and $\mathrm{PCl}$ at different molar ratios; solvent: $\mathrm{C}_{5} \mathrm{D}_{5} \mathrm{~N}$.

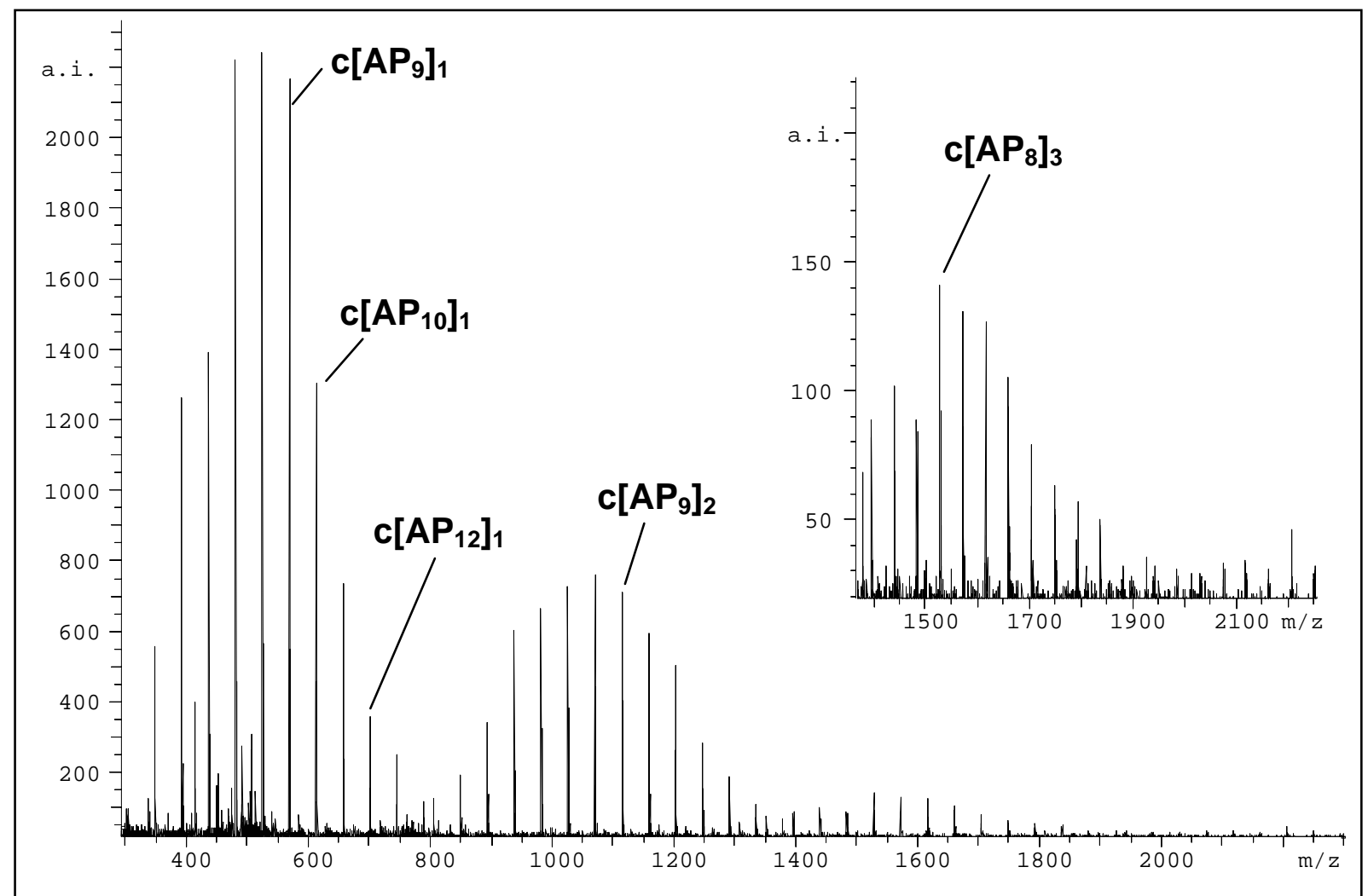

c: macrocycle; A: pyridine dicarboxylate group; $P_{n}$ : poly(ethylene oxide) sequence with ( $n$ ) repetitive units; the number following $c\left[\mathrm{AP}_{\mathrm{n}}\right]$ denotes the degree of polymerization

Fig. 2. MALDI-TOF mass spectrum of the polyester obtained for the reaction of pyridine-2,6-dicarboxylic acid with PEG 400 using a $[\mathrm{PCl}] /[\mathrm{COOH}]$ molar ratio of 1.25 after a reaction time of $50 \mathrm{~h}\left(\mathrm{n}^{\circ} 6, \mathrm{Tab}^{2}\right)$.

This spectrum exhibits three series of peaks resulting from the polymer nature of the PEG used as comonomer. Each envelope is assigned to structures with one, two and 
three PEG moieties according to increasing $\mathrm{m} / \mathrm{z}$. Signals correspond to the $\mathrm{Na}^{+}$ doped macromolecules. The difference between two neighbouring signals in a series is 44.06 corresponding to one $-\mathrm{CH}_{2} \mathrm{CH}_{2} \mathrm{O}$ - unit (calc. 44.02) of poly(ethylene glycol). The MALDI-TOF mass spectrum revealed that the predominant reaction products are cyclic oligomers resulting from cyclization that occurs in almost all polycondensation reactions [15]. Only one linear structure $[P A]_{2} \mathrm{P}$ was detected. The absence of signals for the linear products $[\mathrm{PA}]_{1}$ or $[\mathrm{PA}]_{1} \mathrm{P}$ in the first steps of the polymerization is attributed to their small quantity.

The predominant formation of macrocycles prevents the chain growth and the increase of the molecular weight of the polymers. These macrocycles may be connected to the successive character of the reactions involved in the formation of the monoacid chloride and the diacid dichloride. Picryl chloride reacts first with pyridine-2,6-dicarboxylic acid. The resulting monoacid chloride can react once more with picryl chloride or with PEG. This last reaction seems to be favored for $[\mathrm{PCl}] /[\mathrm{COOH}]$ molar ratios $<1.5$. Once the monoacid chloride has reacted with $\mathrm{PEG}$, it can directly lead to a macrocycle as soon as the second acid is activated. The production of linear chains is by the way disfavoured.

More surprising is the limitation of $\overline{\mathrm{M}_{n}}$ when $[\mathrm{PCl}] /[$ diacid] molar ratio is higher than 1.5 (no.8 and 9, Tab. 2). In fact, the $\overline{M_{n}}$ of the polycondensate obtained for $a$ $[\mathrm{PCl}] /[\mathrm{COOH}]$ molar ratio of 2 is limited to $2800 \mathrm{~g} \mathrm{~mol}^{-1}$ (no.9, Tab. 2) as determined by SEC. The MALDI-TOF mass spectrum of the resulting product (not shown) revealed the existence of the linear product $[A P]_{1}$ and the macrocycle $c[A P] 1$. Only mass peaks of condensates with one poly(ethylene oxide) sequence were detectable. The excess amount of picryl chloride compared to complete activation of acid functions may favour the formation of the pyridinium salt of picryl chloride with pyridine [14].

The most favorable [PCl]/[diacid] molar ratio of 1.5 for synthesis of high molecular weight polyesters has been used for the following polycondensations.

The medium concentration can also be an important factor in obtaining cyclic and/or linear polyesters. Tab. 3 shows the effect of the medium concentration on the molecular weight of the polyesters. Pyridine acts at once as solvent and as base, which traps the $\mathrm{HCl}$ formed during the reaction. The medium concentration was found to have no marked influence on the $\bar{M}_{n}$ of the obtained polyesters. When PEG 6000 was used instead of PEG 400 (Tab. 4), better results are obtained with a lower concentration $\left(0.1 \mathrm{~mol} \mathrm{~L} \mathrm{~L}^{-1}\right.$ compared to $\left.0.33 \mathrm{~mol} . \mathrm{L}^{-1}\right)$. In this case, medium concentration might be favourable for a better solubility of the high molecular weight dialcohol.

The use of 4-(N,N-dimethylamino)pyridine (DMAP) [16-17], a more efficient $\mathrm{HCl}$ trap has been tested. No polycondensation occurs for the reaction conducted with a $[\mathrm{PCl}] /[\mathrm{COOH}]$ molar ratio of 1.5 , a medium concentration in pyridine of $0.33 \mathrm{~mol} . \mathrm{L}^{-1}$ and a DMAP concentration of $0.66 \mathrm{~mol}^{-\mathrm{L}^{-1}}$ at room temperature because the mixture immediately solidified. In the same way, no polyester was obtained by the use of a catalytic amount of DMAP as reported in literature [17]. On the contrary, a reaction temperature of $50^{\circ} \mathrm{C}$ allows to reach a polycondensate of higher $\overline{M_{n}}$ (60300) when DMAP is used as $\mathrm{HCl}$ trap instead of pyridine $\left(\overline{\mathrm{M}_{n}}=33100\right)$ after a reaction time of 50 h. 
Tab. 3. Effect of medium concentration on reaction of pyridine-2,6-dicarboxylic acid and PEG 400; solvent: pyridine; $[\mathrm{PCl}] /[\mathrm{COOH}]=1.5$; reaction time $=50 \mathrm{~h}$.

\begin{tabular}{cccc}
\hline Medium concentration (mol. $\left.{ }^{-1}\right)$ & $\overline{\mathrm{M}}_{\mathrm{n}}$ a) & $\left.\mathrm{M}_{\mathrm{p}}{ }^{\mathrm{a}, \mathrm{b}}\right)$ & PDI \\
\hline 0.5 & 31900 & 34700 & 3.2 \\
0.33 & 33100 & 39400 & 3.2 \\
0.17 & 26700 & 28600 & 2.7
\end{tabular}

a) Obtained by SEC calibrated with polystyrene standards. b) Mp: molecular weight at the peak maximum of the SEC trace.

This efficient method of polycondensation has been successfully applied for a series of aliphatic and aromatic comonomers (Tab. 4) by using the following mild reaction conditions: $[\mathrm{PCl}] /[\mathrm{COOH}]$ molar ratio of 1.5 , reaction time of $50 \mathrm{~h}$, room temperature and atmospheric pressure.

Tab. 4. Physico-chemical characterization of polyesters obtained from poly condensations between pyridine-2,6-carboxylic acid, 4,4'-dicarboxy-2,2'-bipyridine or succinic acid and flexible segments (PEGs).

\begin{tabular}{|c|c|c|c|c|c|c|c|}
\hline \multicolumn{2}{|c|}{ Comonomer } & \multicolumn{3}{|c|}{ SEC $^{a)}$} & \multirow{2}{*}{$\begin{array}{l}{[\eta]_{\text {inh }}{ }^{c)}} \\
\left(d L \cdot g^{-1}\right)\end{array}$} & \multirow{2}{*}{$\begin{array}{c}\mathrm{Tg} \\
\left({ }^{\circ} \mathrm{C}\right)\end{array}$} & \multirow{2}{*}{$\begin{array}{l}\mathrm{Tm} \\
\left({ }^{\circ} \mathrm{C}\right)\end{array}$} \\
\hline Diacid & Dialcohol & $\overline{M_{n}}$ & $M_{p}^{b)}$ & PDI & & & \\
\hline \multirow{3}{*}{ No diacid } & PEG 400 & $-d)$ & -d) & d) & 0.03 & - & 5 \\
\hline & PEG 1000 & 1460 & 1540 & 1.04 & 0.07 & -61 & 36 \\
\hline & PEG 6000 & 9700 & 10300 & 1.03 & 0.18 & -36 & 56 \\
\hline \multirow[b]{3}{*}{$\mathrm{HOOC}_{\mathrm{COOH}}$} & PEG 400 & 33100 & 39400 & 3.2 & 0.27 & -30 & $-f^{\prime}$ \\
\hline & PEG 1000 & -d) & 45000 & $-d)$ & 0.38 & -f) & 168 \\
\hline & PEG 6000 & d) & 80000 & -d) & 0.50 & -44 & 51 \\
\hline \multirow{3}{*}{$\mathrm{COOH}$} & PEG 400 & 4400 & 4800 & 1.4 & 0.16 & -44 & 146 \\
\hline & PEG 1000 & 8600 & 10500 & 1.5 & 0.25 & -50 & 123 \\
\hline & PEG 6000 & e) & e) & -e) & 0.36 & f) & 61 \\
\hline $\mathrm{HOOC}\left(\mathrm{CH}_{2}\right)_{2} \mathrm{COOH}$ & PEG 1000 & 9720 & 14700 & 1.5 & 0.21 & $\left.-f^{f}\right)$ & 150 \\
\hline
\end{tabular}

a) Obtained by SEC calibrated with polystyrene standards. b) $\mathrm{Mp}$ : molecular weight at the peak maximum of the SEC trace. c) Solvent NMP, concentration $C=0.49 \mathrm{~g} \mathrm{dL}^{-1}, 35^{\circ} \mathrm{C}$. d) A part of the SEC trace is outside the calibration curve. e) Polymer insoluble in THF. f) not detected.

The results confirm the efficiency of this method compared to polycondensations of pyridine-2,6-carboxylic acid and PEG either by using DCC and DMAP $\left(\overline{\mathrm{M}}_{\mathrm{n}}=1\right.$ 150), or starting from diacid dichloride as reported in the literature [3] $\left(\bar{M}_{n}=7030\right)$. Polyesters exhibit glass transition temperatures $\mathrm{Tg}$ (Table 4) between $-30^{\circ} \mathrm{C}$ and $50^{\circ} \mathrm{C}$ but no relationship can be established with the $\mathrm{Tg}$ of the starting PEG. 


\section{Conclusions}

We have synthesized polyesters of both high conversion and high number-average molecular weight from an aromatic diacid and aliphatic dialcohols of various lengths by a direct polycondensation under mild conditions (at room temperature under atmospheric pressure) using picryl chloride as condensing agent with a $[\mathrm{PCl}] /[\mathrm{COOH}]$ molar ratio of 1.5 with pyridine used as solvent and $\mathrm{HCl}$ trap. These conditions have successfully been used to synthesize aliphatic and aromatic polyesters. Use of a $[\mathrm{PCl}] /[\mathrm{COOH}]$ molar ratio less than 1.5 with $\mathrm{PEG} 400$ as comonomer has led to a high fraction of macrocycles as detected by MALDI-TOF mass spectrometry.

\section{Experimental part}

\section{Materials}

Solvents were purified by conventional procedures as described in literature [18]. 4,4'-dicarboxy-2,2'-bipyridine [19] and picryl chloride [20] were synthesized according to a literature procedure. Poly(ethylene glycol)s 400, 1000 and 6000 purchased from Acros Organics were dried as already described [6]. Unless otherwise specified, all the reagents were used as received without further purification.

\section{Characterization}

NMR spectra were recorded on a Bruker AC-400 spectrometer for ${ }^{1} \mathrm{H}$ NMR (400 $\mathrm{MHz}$ ) and ${ }^{13} \mathrm{C}$ NMR (100.6 MHz). Molecular weights and molecular weight distributions were measured using size exclusion chromatography (SEC) on a system equipped with a SpectraSYSTEM AS 1000 autosampler, with a guard column (Polymer Laboratories, PL gel $5 \mu \mathrm{m}$ Guard column, $50 \times 7.5 \mathrm{~mm}$ ) followed by two columns (Polymer Laboratories, 2 PL gel $5 \mu \mathrm{m}$ MIXED-D columns, 2x300x7.5 mm), with a SpectraSYSTEM RI-150 detector. The eluent used was THF at a flow rate of 1 $\mathrm{mL} . \mathrm{min}^{-1}$ at $35^{\circ} \mathrm{C}$. Polystyrene standards $\left(580-483 \times 10^{3} \mathrm{~g} \cdot \mathrm{mol}^{-1}\right)$ were used to calibrate the SEC. MALDI experiments were performed using a Bruker Biflex III MALDI-TOF mass spectrometer. The matrix, dithranol (DIT), was dissolved in methanol $(10 \mathrm{mg}$ $\left.\mathrm{mL}^{-1}\right)$ and the solution was mixed with the polymer solution (10 $\mathrm{mg} \mathrm{mL}^{-1}$ in methanol) in a 10:1 v/v ratio. $1 \mu \mathrm{L}$ analyte solution was spotted directly onto the thin-layer formed by depositing $1 \mu \mathrm{L}$ saturated Nal cationizing agent in acetone. The intrinsic viscosities were measured in $N$-methyl-2-pyrrolidone using an Ubbelohde viscometer thermostated at $25^{\circ} \mathrm{C}$, with a solution concentration of $0.49 \mathrm{~g} \mathrm{dL}^{-1}$. Thermal analyses were performed under a nitrogen atmosphere on a differential scanning calorimetry (DSC) analyzer (DSC Q100 TA Instrument) with a heating rate of $10^{\circ} \mathrm{C} / \mathrm{min}$.

\section{General procedure of the synthesis of polyesters using picryl chloride}

The synthesis of polyesters is described here as the general procedure. Into a $25 \mathrm{~mL}$ round-bottom flask, $1 \mathrm{mmol}$ of diol was added to a solution of diacid $(1 \mathrm{mmol})$ and picryl chloride $(3 \mathrm{mmol})$ in pyridine $(3 \mathrm{~mL}, 17 \mathrm{mmol})$ at room temperature. The reaction mixture was stirred at room temperature for $50 \mathrm{~h}$. The solution was poured into rapidly stirred diethyl ether-methanol (1/1) mixture. The precipitated polymer was filtered and dried at $30^{\circ} \mathrm{C}$ under vacuum for 1 day.

\section{References}

[1] Whinfield J. R.; Nature 1946, 158, 930.

[2] Kibler C. J.; Bell A.; Smith J. G.; J. Polym. Sci. Part A 1964, 2, 2115. 
[3] Ignatova M.; Manolova N.; Rashkov I.; Sepulchre M.; Spassky N.; Macromol. Chem. Phys. 1995, 196, 2695.

[4] Yu, S.C.; Hou, S.; Chan, W.K.; Macromolecules 2000, 33, 3259.

[5] Sanui K.; Tanaka S.; Ogata N.; J. Polym. Sci., Polym.: Chem. Ed. 1977, 15, 1107.

[6] Soutif J.-C.; Doan T. H. N.; Montembault V.; Eur. Polym. J. 2006, 42, 126.

[7] Yasuda S.; Wu G. C.; Tanaka H.; Sanui K.; Ogata N.; J. Polym. Sci.: Polym. Chem. Ed. 1983, 21, 2609.,

[8] Higashi F.; Mashimo T.; Takahashi I.; J. Polym. Sci.: Polym.: Chem. Ed. 1986, 24, 97.

[9] Elias H. G.; Warner R. J.; Macromol. Chem. 1981,182, 681.

[10] Higashi F.; Nishi T.; J. Polym. Sci.: Polym. Chem. Ed. 1986, 4, 701.

[11] Higashi F.; Haramoto S.; Yashio M.; Macromol. Chem. Phys. 2002, 203, 309.

[12] Takimoto S.; Inanaga J.; Katsuki T.; Yamaguchi M.; Bull. Chem. Soc. Japan 1981, 54, 1470.

[13] Tanaka H.; Wu G. C.; Iwanaga Y.; Sanui K.; Ogata N., Polym. J. 1982, 14, 331.

[14] Tanaka H.; Iwanaga Y.; Wu G. C.; Sanui K.; Ogata N.; Polym. J. 1982, 14, 643.

[15] Eichinger B. E.; Comp. Theor. Polym. Sci. 2000, 10, 83.

[16] Lee S. Y.; Chin I. J.; Jung J. S.; Eur. Polym. J. 1999, 35, 2147.

[17] Plamper F. A.; Becker H.; Lanzendörfer, M.; Patel M.; Wittemann A.; Ballauf M.; Müller A. H. E.; Macromol. Chem. Phys. 2005, 206, 1813.

[18] Perrin D. D; Armarego W. L. F.; Perrin D. R.; Purification of Laboratory Chemicals. New York: Pergamon Press, $2^{\text {nd }} E d .1980$.

[19] Bos K. D.; Kraaijkamp J. G.; Noltes J. G.; Synth. Commun. 1979, 9, 497.

[20] Raymond B.; Spencer E. Y.; Wright G. F.; Can. J. Research 1946, 24B, 200. 